\title{
Investigating the Effects of Hearing Loss and Hearing Aid Digital Delay on Sound-Induced Flash Illusion
}

\author{
Vahid Moradi ${ }^{1}$, Kiana Kheirkhah ${ }^{2}$, Saeid Farahani ${ }^{1}$, and Iman Kavianpour ${ }^{3}$ \\ ${ }^{1}$ Department of Audiology, School of Rehabilitation, Tehran University of Medical Sciences, Tehran, Iran \\ ${ }^{2}$ Department of Biomedical Engineering, School of Electrical and Computer, Islamic Azad University, Tehran, Iran \\ ${ }^{3}$ Department of Telecommunication, School of Engineering Boushehr Branch, Islamic Azad University, Boushehr, Iran
}

Received December 22, 2019

Revised April 10,2020

Accepted April 28, 2020

Address for correspondence

Saeid Farahani, $\mathrm{PhD}$

Department of Audiology,

School of Rehabilitation,

Tehran University of

Medical Sciences, Pich-e-Shemiran,

Enghelab Avenue, Tehran 0098, Iran

Tel +98-21-77530636

Fax +98-21-77684889

E-mail_s_farahani@tums.ac.ir
Background and Objectives: The integration of auditory-visual speech information improves speech perception; however, if the auditory system input is disrupted due to hearing loss, auditory and visual inputs cannot be fully integrated. Additionally, temporal coincidence of auditory and visual input is a significantly important factor in integrating the input of these two senses. Time delayed acoustic pathway caused by the signal passing through digital signal processing. Therefore, this study aimed to investigate the effects of hearing loss and hearing aid digital delay circuit on sound-induced flash illusion. Subjects and Methods: A tota of 13 adults with normal hearing, 13 with mild to moderate hearing loss, and 13 with moderate to severe hearing loss were enrolled in this study. Subsequently, the sound-induced flash illusion test was conducted, and the results were analyzed. Results: The results showed that hearing aid digital delay and hearing loss had no detrimental effect on sound-induced flash illusion. Conclusions: Transmission velocity and neural transduction rate of the auditory inputs decreased in patients with hearing loss. Hence, the integrating auditory and visual sensory cannot be combined completely. Although the transmission rate of the auditory sense input was approximately normal when the hearing aid was prescribed. Thus, it can be concluded that the processing delay in the hearing aid circuit is insufficient to disrupt the integration of auditory and visual information.

J Audiol Otol 2020;24(4):174-179

KEY WORDS: Hearing loss · Auditory-visual integration · Sound-induced flash illusion · Hearing aid $\cdot$ Temporal coincidence.

\section{Introduction}

All activities required for perception and recognition of the various auditory and visual stimuli depend on the accurate discovery of events [1]. Each of the senses in the body can work together, in addition to acting alone, and their combination can help a person in discovering what has happened more accurately and comprehensively [2]. In the auditory system, the sound is delivered through the cochlea to the auditory nerve, and the auditory signal eventually reaches the surface of the auditory cortex. Thus, the person recognizes the acoustic stimulus [3]. Interaction between the auditory and

This is an Open Access article distributed under the terms of the Creative Commons Attribution Non-Commercial License (https://creativecommons.org/licenses/by-nc/4.0/) which permits unrestricted non-commercial use, distribution, and reproduction in any medium, provided the original work is properly cited. visual senses is one of the multisensory interactions in humans. In this situation, information from the auditory and visual systems is combined in the occipital, temporal, frontal, and parietal cortex, which might change the essential nature of both visual and auditory stimuli [4]. For example, according to the McGurk effect, combined information from the auditory and visual systems influences speech perception. If the auditory /ba/ and visual /ga/ stimuli are presented simultaneously, the person will eventually hear /da/ [2]. This phenomenon is considered a comprehensive example of how auditory and visual information integrate at the upper levels of auditory and visual processing [5]. Shams, et al. [6] introduced the sound-induced flash illusion (SIFI) phenomenon. In this phenomenon, acoustic stimulation has an influence on the perception of visual stimuli. In the SIFI test, naive volunteers are presented with a flash stimulus, and they are simultane- 
ously provided with an audio stimulus so that the naive volunteers only see one flash. Nevertheless, when a flash is presented during two audio stimuli, the naive volunteers would admit that they see two flashes [6]. It has been stated that the visual illusion can be caused by the presentation of acoustic stimuli.

This illusion indicates the integration of visual and auditory information at the upper levels of the auditory and visual cortex [7]. Studies have shown that SIFI is not influenced by the frequency of stimuli [6] and feedback training [8]. Therefore, this phenomenon has been proven to result from the modulation of activity on the surfaces of the visual cortex and superior temporal gyrus such that neuroimaging techniques such as functional magnetic resonance imaging have confirmed increased activity in the visual cortex during the occurrence of SIFI [9]. All of the studies in this field have conducted the SIFI test in individuals with normal hearing [6]. However, a study assessing SIFI in patients with hearing loss problems has not been conducted yet. In a person with hearing impairment, the amount of input voice decreases, resulting to a decrease in the neural firing rate and neural transmission time [10]. Hearing aids are prescribed depending on the degree of hearing loss, and with the use of the hearing aid, patients with hearing impairment will be able to hear voices previously deprived of them. However, the deleterious effects of hearing aid digital delay depend on the degrees of hearing loss [11]. The temporal association between auditory and visual stimuli is a significantly important factor in encoding the integration between the auditory and visual stimuli [12]. Auditory and visual stimuli can be integrated together up to $100 \mathrm{~ms}$ of time window. If the time window increases, auditory, and visual stimuli cannot be combined, and the brain processes auditory and visual stimuli separately $[13,14]$. Hearing loss and hearing aid digital delay can influence the time window and auditory and visual integration [15]. Accordingly, the present study aimed to investigate and analyze the effects of different degrees of hearing loss and hearing aid digital delay on the SIFI test results.

\section{Subjects and Methods}

\section{Participants}

All the participants were recruited from the Najva Audiology Clinic. The participants were divided into three groups including the following: 13 volunteers (seven females and six males, with a mean age of 33.77 years) with normal hearing in both ears (Group 1), 13 volunteers (five females and eight males, with a mean age of 45.77 years) with bilateral symmetrical mild to moderate sensorineural hearing loss
(Group 2), and 13 volunteers (six females and seven males, with a mean age of 43.54 years) with bilateral symmetrical moderate to severe sensorineural hearing loss (Group 3). Each of the participants in Groups 2 and 3 had at least 6 months of hearing aid experience [16]. All of the participants had normal or corrected-to-normal vision in normal range [17] and had no history of mental disorders or brain diseases [1] and middle ear infection [18].

Table 1 shows the mean hearing threshold at frequencies of $500,1,000,2,000$, and 4,000 $\mathrm{Hz}$ for the right and left ears, with respect to sex and age of the participants in the normal hearing group. Moreover, Table 2 and 3 present the mean hearing threshold and aided hearing threshold at frequencies of 500, 1,000, 2,000, and 4,000 $\mathrm{Hz}$ for the right and left ears, with respect to sex, age, duration of wearing the hearing aids, and hearing aid brands of the participants in Groups 2 and 3, respectively.

Before starting the study, all of the participants were reexamined to assess their hearing and visual thresholds by repeating the hearing test at a frequency of $250-8,000 \mathrm{~Hz}$. Moreover, the aided hearing thresholds were assessed for the participants in Groups 2 and 3 to accurately assess their normal hearing threshold using the hearing aid. The vision of the participants was also assessed using the Snellen eye chart to appropriately evaluate their normal vision [17]. An informed written consent was obtained from the participants. The study was approved by the Human Research Ethics Committee of Tehran University of Medical Sciences (IR.TUMS. FNM.REC.1398.139), and it was conducted in accordance with the Declaration of Helsinki (1975) and its later amendments.

Table 1. Demographic data of participants with normal hearing

\begin{tabular}{ccccc}
\hline Subject & Sex & Age $(\mathrm{yr})$ & Right PTA $(\mathrm{dB})$ & Left PTA $(\mathrm{dB})$ \\
\hline S1 & $\mathrm{F}$ & 21 & 10 & 7.5 \\
S2 & $\mathrm{M}$ & 28 & 13.75 & 15 \\
S3 & $\mathrm{F}$ & 37 & 1.25 & 2.5 \\
S4 & $\mathrm{F}$ & 22 & 11.25 & 11.25 \\
S5 & $\mathrm{M}$ & 41 & 3.75 & 5 \\
S6 & $\mathrm{F}$ & 39 & 20 & 21.25 \\
S7 & $\mathrm{F}$ & 25 & 11.25 & 11.25 \\
S8 & $\mathrm{M}$ & 31 & 20 & 20 \\
S9 & $\mathrm{M}$ & 38 & 7.5 & 5 \\
S10 & $\mathrm{M}$ & 44 & 12.5 & 11.25 \\
S11 & $\mathrm{F}$ & 37 & 5 & 2.50 \\
S12 & $\mathrm{F}$ & 34 & 11.25 & 7.50 \\
S13 & $\mathrm{M}$ & 44 & 12.50 & 11.25 \\
Average & & 33.77 & 10.09 & 9.80 \\
\hline F: & & 34 &
\end{tabular}

F: female, $M$ : male, yr: years, PTA: pure tone average, $d B$ : decibel 
Table 2. Demographic data of participants with mild to moderate hearing loss

\begin{tabular}{ccccccccc}
\hline Subject & Sex & Age $(\mathrm{yr})$ & HAU $(\mathrm{yr})$ & Hearing aid brand & $\begin{array}{c}\text { Right PTA } \\
(\mathrm{dB})\end{array}$ & $\begin{array}{c}\text { Right aided } \\
\text { hearing }(\mathrm{dB})\end{array}$ & $\begin{array}{c}\text { Left PTA } \\
(\mathrm{dB})\end{array}$ & $\begin{array}{c}\text { Left aided } \\
\text { hearing }(\mathrm{dB})\end{array}$ \\
\hline S1 & M & 34 & 3 & Bernafon & 21.25 & 21.25 & 42.50 & 20.00 \\
S2 & M & 57 & 5 & Siemens & 20.00 & 20.00 & 43.75 & 20.00 \\
S3 & F & 49 & 5 & Bernafon & 20.00 & 20.00 & 46.25 & 20.00 \\
S4 & M & 44 & 4 & Widex & 21.25 & 21.25 & 42.50 & 21.25 \\
S5 & F & 24 & 7 & Siemens & 22.50 & 22.50 & 43.75 & 21.25 \\
S6 & F & 59 & 5 & Oticon & 20.00 & 20.00 & 46.25 & 20.00 \\
S7 & M & 54 & 2 & Bernafon & 22.50 & 22.50 & 51.25 & 23.75 \\
S8 & M & 46 & 5 & Oticon & 20.00 & 20.00 & 37.5 & 21.25 \\
S9 & F & 58 & 8 & Siemens & 20.00 & 20.00 & 43.75 & 20.00 \\
S10 & M & 41 & 2 & Sonic & 21.25 & 21.25 & 41.25 & 20.00 \\
S11 & M & 44 & 4 & Hansaton & 21.25 & 21.25 & 42.50 & 21.25 \\
S12 & M & 48 & 6 & Oticon & 22.50 & 22.50 & 45.00 & 21.25 \\
S13 & F & 37 & 8 & Unitron & 21.25 & 21.25 & 46.25 & 22.50 \\
Average & & 45.77 & 4.92 & & 42.40 & 21.02 & 43.65 & 20.75 \\
\hline
\end{tabular}

F: female, M: male, yr: years, PTA: pure tone average, dB: decibel, HAU: hearing aid use

Table 3. Demographic data of participants with moderate to severe hearing loss

\begin{tabular}{ccccccccc}
\hline Subject & Sex & Age $(\mathrm{yr})$ & HAU (yr) & Hearing aid brand & $\begin{array}{c}\text { Right PTA } \\
(\mathrm{dB})\end{array}$ & $\begin{array}{c}\text { Right aided } \\
\text { hearing }(\mathrm{dB})\end{array}$ & $\begin{array}{c}\text { Left PTA } \\
(\mathrm{dB})\end{array}$ & $\begin{array}{c}\text { Left aided } \\
\text { hearing }(\mathrm{dB})\end{array}$ \\
\hline S1 & M & 57 & 7 & Oticon & 60.00 & 22.50 & 65.00 & 21.25 \\
S2 & F & 54 & 6 & Oticon & 62.50 & 21.25 & 66.25 & 22.50 \\
S3 & M & 57 & 11 & Bernafon & 55.00 & 20.00 & 52.50 & 21.25 \\
S4 & F & 49 & 8 & Resound & 58.75 & 21.25 & 57.50 & 22.50 \\
S5 & M & 27 & 9 & Siemens & 58.75 & 22.50 & 56.25 & 20.00 \\
S6 & F & 35 & 5 & Belton & 65.00 & 21.25 & 62.50 & 21.25 \\
S7 & M & 18 & 15 & Oticon & 52.50 & 22.50 & 50.00 & 22.50 \\
S8 & M & 39 & 5 & Bernafon & 56.25 & 21.25 & 63.75 & 21.25 \\
S9 & F & 52 & 10 & Phonak & 57.50 & 21.25 & 65.00 & 21.25 \\
S10 & F & 35 & 7 & Oticon & 56.25 & 22.50 & 57.50 & 23.75 \\
S11 & F & 52 & 9 & Oticon & 58.75 & 23.75 & 57.50 & 25.00 \\
S12 & M & 49 & 5 & Resound & 55.00 & 22.50 & 55.00 & 21.25 \\
S13 & M & 42 & 4 & Hansaton & 60.00 & 21.25 & 62.50 & 22.50 \\
Average & & 43.54 & 4.23 & & 58.17 & 21.25 & 59.32 & 21.76 \\
\hline
\end{tabular}

F: female, M: male, yr: years, PTA: pure tone average, dB: decibel, HAU: hearing aid use

\section{Experimental procedure}

In performing the SIFI test, all the required parameters and points for test design using the MATLAB software (R2019b, MathWorks, Natick, MA, USA) were selected according to Shams, et al. [6]. The frequency of beep was equal to 3,500 $\mathrm{Hz}$ with $7 \mathrm{~ms}$ of duration at $95 \mathrm{~dB}$ sound pressure level (SPL) provided by the two speakers, one speaker on each side of the monitor, and the two speakers were placed $58 \mathrm{~cm}$ apart. The time interval between the beeps was equal to 57 $\mathrm{ms}$, and the beeps were always provided $23 \mathrm{~ms}$ before the flashes. Flashes were presented with $17 \mathrm{~ms}$ of duration and $108 \mathrm{~cd} / \mathrm{m}^{2}$ of luminance at a 2-degree angle of 5 degrees of visual field eccentricity on a $0.02 \mathrm{~cd} / \mathrm{m}^{2}$ luminaire black plate. Furthermore, the time interval between the flash presentations was equal to $50 \mathrm{~ms}$. During the test, the participants were instructed to sit on a $60-\mathrm{cm}$ chair away from the laptop monitor (model ASUS X550, Taipei, Taiwan) and to focus on the screen continuously to count the number of flashes. The test was performed in a dome-lighted room and acoustic environment with $42 \mathrm{~dB}$ of background noise [17]. Participants were instructed to turn off their cell phones in the test room. Frequency and intensity were checked using the sound level meter (Bruel \& Kjaer, 2235 manual; https:// www.bksv.com/en/products/sound-and-vibration-meters/ sound-level-meters-and-vibration-meters). In the single flash test, a flash was provided with $0-4$ beeps, and in multiple 
flash test, 1-4 flashes were provided with $0-1$ beeps. Each of these tests was randomly performed 5 times by the participants, and a total of 65 trials were performed. All the tests were performed in the three study groups, and the data were analyzed.

\section{Statistical analyses}

Data analysis was performed using the Statistical Package for the Social Sciences version 22 software (SPSS, New York, NY, USA). Normality of data was evaluated using the Kolmogorov-Smirnov test. Analysis of variance (ANOVA) was used to compare the mean flash illusion between the three study groups, and if the ANOVA results were significant, the Tukey's post-hoc test was used for pairwise comparison. A $p$ value of 0.05 was considered statistically significant.

\section{Results}

According to the results, the participants saw one flash in all the study groups while a flash was presented with $0-1$ beeps (Trial 1). Therefore, when the number of beeps increased up to 2-4 (Trial 2), the number of perceived flashes observed by the participants in all the study groups increased, although only one flash was presented. There was a statistically significant difference between the two trials $(p<0.001)$ in all the study groups, which was referred to as visual illusion.

Nevertheless, there was no statistically significant differ- ence between the study groups ( $p=0.999)$. Fig. 1 shows the mean number of perceived flashes for one flash and $0-4$ beeps provided for all the studied participants.

In the multiple flash test, only the number of flashes increased, and the number of beeps remained constant. These results are contrary to those of the single flash test, and perceived flashes demonstrated that the participants could dis-

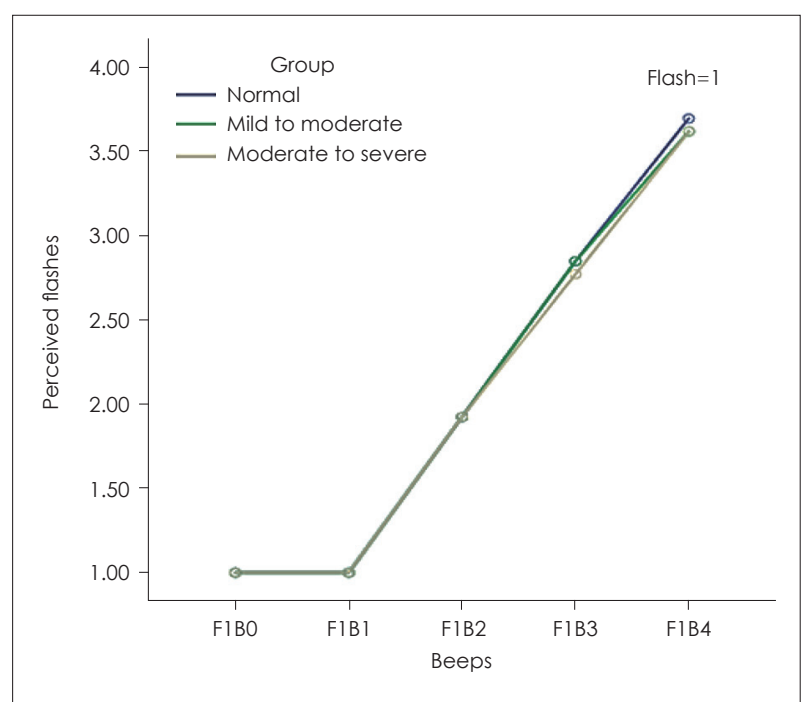

Fig. 1. The average number of perceived flashes for the three groups. As observed, the average perceived flashes for the normal hearing and hearing loss groups are similar. Moreover, significant differences in perceived flashes for participants with different hearing loss severities are not observed. F: flashes, B: beeps.

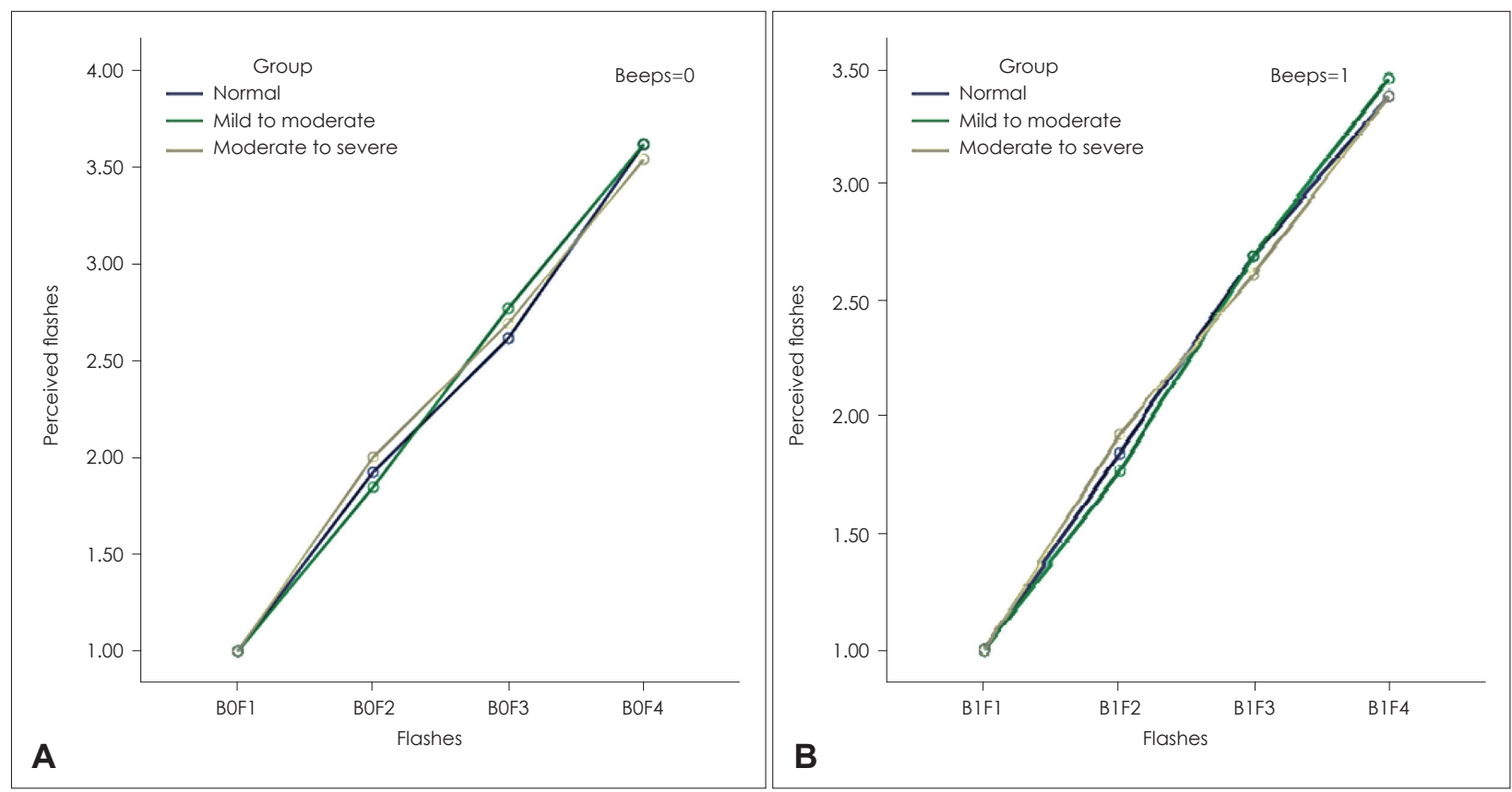

Fig. 2. The average number of perceived flashes for 0 beep $(A)$ and 1 beep (B) are shown for the three groups. As observed, the average perceived flashes for the normal hearing and hearing loss groups are similar in 0 beep and 1 beep. Moreover, significant differences in perceived flashes for participants with different hearing loss severities are not observed. F: flashes, B: beeps. 
tinguish the correct number of flashes when the number of beeps remained constant. Fig. 2 shows the results of the multiple flash test. Fig. 2A shows the mean number of perceived flashes when no beeps were presented, and the number of flashes varied (from 1 to 4 ). Fig. 2B shows the mean number of perceived flashes when one beep was presented, and the number of flashes varied (from 1 to 4 ).

The mean number of perceived flashes in the multiple flash test was similar in Fig. 2A and B, and the mean number of perceived flashes increased in all the three groups by increasing the number of flashes as shown in Fig. 2A. There was no statistically significant difference between the two groups $(p=0.836)$. Moreover, the mean number of perceived flashes increased in all the three groups by increasing the number of flashes as shown in Fig. 2B. There was no statistically significant difference between the two groups ( $p=0.937$ ).

The responses of the participants in the multiple flash test were contrary to the number of beeps, which they heard in the single flash test, since it can be certainly confirmed that the responses in the single flash test were based on visual perception and were not influenced by the auditory cognitive biases.

\section{Discussion}

This study was conducted to investigate the effects of different degrees of hearing loss on the SIFI test results; however, all of the previous studies have conducted the SIFI test in individuals with normal hearing. Herein, the effects of digital hearing aid digital delay were also investigated on the temporal coincidence between auditory and visual signals. Temporal coincidence is one of the most important factors contributing to the integration of auditory and visual information in the temporal and occipital cortex [19]. When two sensory stimuli are presented, a specific window is defined for the input of these two systems [14]. However, if the time between the two stimuli exceeds, then the input cannot be integrated. Finally, each sensory stimulus just reaches its own cortical region, and sensory stimuli will not be perceived as multisensory signal [20]. The window defined for the integration of the auditory and visual sensory inputs is less than $100 \mathrm{~ms}$ of duration $[13,14]$. Nevertheless, if the interval between these two stimuli is greater than $100 \mathrm{~ms}$, then the audiovisual multisensory integration will not occur [20]. The sensitivity of cochlear hair cells decreases for soft sound in the hearing-impaired patients; therefore, transmission of the sound from the peripheral hearing system to the central system is delayed [21]. However, when the hearing aid is prescribed based on the severity of hearing loss, the sound is amplified, and this delay is compensated for the peripheral hearing system [22]. The temporal processing between visual and auditory stimuli has different velocities in the peripheral and central systems [23]. The speed of light sensory receptors in the eye is faster than that of sound sensory receptors in the cochlear; in contrast, the speed of sound is faster than the light when the input is transferred from the peripheral to the central system [23]. Therefore, any factor reducing the transmission rate of auditory or visual input can highly influence the multisensory processing [24]. Hearing loss leads to the reduction of the speed of auditory stimuli, which in turn causes a delay in transmission of the sound from the peripheral auditory system to the central auditory system [25]. Hence, the auditory and visual stimuli cannot be integrated [26]. If the hearing aid is prescribed, this delay is minimized due to the appropriate amplification applied at different frequencies. The results of this study showed no significant difference in the visual-auditory integration between the hearing aid users and participants with normal hearing.

Furthermore, when disturbance occurs in the auditory and visual sensory systems, the central processing system minimizes the delays by making certain changes, but if the central system itself is influenced, it cannot aid in reintegrating the auditory and visual inputs, which is observed in schizophrenic patients [17]. Humes, et al. [26] reported that the temporal discrimination threshold will be increased with increasing age. Diederich, et al. [27] showed that aging causes the temporal window of sensory input integration to become longer. It seems that, with the decrease in the sensitivity of the peripheral sensory system, the central system changes the central system's processing to protect the multisensory information and to provide the conditions for the integration of multisensory information [1].

As mentioned earlier, the transmission rate of auditory input decreases in the hearing-impaired patients, making it difficult to integrate the auditory and visual sensory inputs. However, the transmission rate of auditory input will be closer to that of the participants with normal hearing, and the integration of auditory and visual inputs will occur with the use of the hearing aid. The delay in digital hearing aid circuit is the second factor influencing the auditory temporal processing in the hearing aid users $[11,28]$. When the hearing aid microphone receives the sound, the sound is converted into digital codes and is delivered in the hearing aid sound processor. At this stage, various processes such as noise reduction and speech signal amplification are applied, and the final information is sent to the hearing aid receiver. At this point, the receiver converts the digital codes into amplified audio signals and sends them to the ear canal, and finally, the patient can hear the amplified sound [11]. Previous studies have shown 
that the sound encounters a slight delay when it enters the microphone until reaching the receiver depending on the processing algorithm of the hearing aid [29]. Eric Lupo, et al. [21] reported that the delay in hearing aid circuit is insufficient to impair the integration of auditory and visual inputs. Thus, it can be concluded that different degrees of hearing loss and digital hearing aid digital delay cannot influence the integration of auditory and visual multisensory information.

In conclusion, the findings of the study indicated that hearing loss and digital hearing aid digital delay cannot influence the SIFI phenomenon. In the present study, participants with asymmetric and unilateral hearing loss were not evaluated, which can be considered as one of the limitations of the study. Rohlfs, et al. [30] stated that the unilateral and asymmetric hearing loss results in the deactivation of the neural encoding during audio-visual integration. Therefore, conducting the SIFI test in patients with asymmetric and unilateral hearing loss is recommended.

\section{Acknowledgments}

The authors would like to thank Prof. Laden Shams for her scientific support during the study.

\section{Conflicts of interest}

The authors have no financial conflicts of interest.

\section{Author Contributions}

Conceptualization: Vahid Moradi. Data curation: Vahid Moradi and Saeid Farahani. Writing — original draft: Vahid Moradi. Writing — review \& editing: Kiana Kheirkhah, Iman Kavianpour, and Vahid Moradi. Approval of final manuscript: all authors.

\section{ORCID iDs}

Vahid Moradi Kiana Kheirkhah

Saeid Farahani

Iman Kavianpour https://orcid.org/0000-0001-8431-3669 https://orcid.org/0000-0002-4468-4227 https://orcid.org/0000-0003-2541-283X https://orcid.org/0000-0003-3710-0956

\section{REFERENCES}

1) Setti A, Stapleton J, Leahy D, Walsh C, Kenny RA, Newell FN. Improving the efficiency of multisensory integration in older adults: audio-visual temporal discrimination training reduces susceptibility to the sound-induced flash illusion. Neuropsychologia 2014;61:259-68.

2) Woodhouse L, Hickson L, Dodd B. Review of visual speech perception by hearing and hearing-impaired people: clinical implications. Int J Lang Commun Disord 2009;44:253-70.

3) Leaver AM, Rauschecker JP. Functional topography of human auditory cortex. J Neurosci 2016;36:1416-28.

4) Bushara KO, Weeks RA, Ishii K, Catalan MJ, Tian B, Rauschecker JP, et al. Modality-specific frontal and parietal areas for auditory and visual spatial localization in humans. Nat Neurosci 1999;2:759-66.

5) De Gelder B, Bertelson P. Multisensory integration, perception and ecological validity. Trends Cogn Sci 2003;7:460-7.

6) Shams L, Kamitani Y, Shimojo S. Visual illusion induced by sound. Brain Res Cogn Brain Res 2002;14:147-52.
7) Shams L, Kamitani Y, Thompson S, Shimojo S. Sound alters visual evoked potentials in humans. Neuroreport 2001;12:3849-52.

8) Rosenthal O, Shimojo S, Shams L. Sound-induced flash illusion is resistant to feedback training. Brain Topogr 2009;21:185-92.

9) Watkins S, Shams L, Tanaka S, Haynes JD, Rees G. Sound alters activity in human $\mathrm{V} 1$ in association with illusory visual perception. Neuroimage 2006;31:1247-56.

10) Tremblay KL, Piskosz M, Souza P. Effects of age and age-related hearing loss on the neural representation of speech cues. Clin Neurophysiol 2003;114:1332-43.

11) Stone MA, Moore BC. Tolerable hearing aid delays. II. Estimation of limits imposed during speech production. Ear Hear 2002;23:325-38.

12) Kamke MR, Vieth HE, Cottrell D, Mattingley JB. Parietal disruption alters audiovisual binding in the sound-induced flash illusion. Neuroimage 2012;62:1334-41.

13) Zampini M, Shore DI, Spence C. Audiovisual temporal order judgments. Exp Brain Res 2003;152:198-210.

14) Zampini M, Guest S, Shore DI, Spence C. Audio-visual simultaneity judgments. Percept Psychophys 2005;67:531-44.

15) Tye-Murray N, Sommers MS, Spehar B. Audiovisual integration and lipreading abilities of older adults with normal and impaired hearing. Ear Hear 2007;28:656-68.

16) Ching TY, Psarros C, Hill M, Dillon H, Incerti P. Should children who use cochlear implants wear hearing aids in the opposite ear? Ear Hear 2001;22:365-80.

17) Overton DJ. Audiovisual integration deficits in schizotypal personality and implications for populations diagnosed with schizophrenia [dissertation]. Toronto: University of Toronto;2015.

18) Holm VA, Kunze LH. Effect of chronic otitis media on language and speech development. Pediatrics 1969;43:833-9.

19) Shams L, Iwaki S, Chawla A, Bhattacharya J. Early modulation of visual cortex by sound: an MEG study. Neurosci Lett 2005;378:76-81.

20) Colonius H, Diederich A. Computing an optimal time window of audiovisual integration in focused attention tasks: illustrated by studies on effect of age and prior knowledge. Exp Brain Res 2011;212:327-37.

21) Eric Lupo J, Koka K, Thornton JL, Tollin DJ. The effects of experimentally induced conductive hearing loss on spectral and temporal aspects of sound transmission through the ear. Hear Res 2011;272: 30-41.

22) Huang S, Tian L, Ma X, Wei Y. A reconfigurable sound wave decomposition filterbank for hearing aids based on nonlinear transformation. IEEE Trans Biomed Circuits Syst 2016;10:487-96.

23) Vroomen J, Keetels M. Perception of intersensory synchrony: a tutorial review. Atten Percept Psychophys 2010;72:871-84.

24) Andersen TS, Tiippana K, Sams M. Factors influencing audiovisual fission and fusion illusions. Brain Res Cogn Brain Res 2004;21:301-8.

25) Hartley DE, Moore DR. Effects of conductive hearing loss on temporal aspects of sound transmission through the ear. Hear Res 2003; 177:53-60.

26) Humes LE, Busey TA, Craig JC, Kewley-Port D. The effects of age on sensory thresholds and temporal gap detection in hearing, vision, and touch. Atten Percept Psychophys 2009;71:860-71.

27) Diederich A, Colonius H, Schomburg A. Assessing age-related multisensory enhancement with the time-window-of-integration model. Neuropsychologia 2008;46:2556-62.

28) Stone MA, Moore BC. Tolerable hearing aid delays. I. Estimation of limits imposed by the auditory path alone using simulated hearing losses. Ear Hear 1999;20:182-92.

29) Pandey A, Mathews VJ. Low-delay signal processing for digital hearing aids. IEEE Trans Audio Speech Lang Process 2010;19:699-710.

30) Rohlfs AK, Friedhoff J, Bohnert A, Breitfuss A, Hess M, Müller F, et al. Unilateral hearing loss in children: a retrospective study and a review of the current literature. Eur J Pediatr 2017;176:475-86. 